\title{
Ramosetron compared with granisetron for the prevention of vomiting following strabismus surgery in children
}

\author{
Yoshitaka Fujii, Hiroyoshi Tanaka, Mutsuko Ito
}

\begin{abstract}
Backgroundlaims-Postoperative vomiting occurs frequently after strabismus surgery in children. Granisetron, a selective 5-hydroxytryptamine type 3 receptor antagonist, is effective for the prevention of vomiting following paediatric strabismus surgery. Ramosetron, another new antagonist of 5-hydroxytryptamine type 3 receptor, has more potent and longer acting properties than granisetron against cisplatin induced emesis. This study was undertaken to compare the efficacy and safety of granisetron and ramosetron for the prevention of vomiting following strabismus surgery in children.
\end{abstract}

Methods-In a randomised, doubh blinded manner 80 children, aged 10 years, received intravenously gran etron $40 \mu \mathrm{g} / \mathrm{kg}$ or ramosetron $6 \mu \mathrm{g} / \mathrm{kg}(\mathrm{n}=4$ each) at the end of surgery. A standard eneral anaesthetic technique and postope tive analgesia were used. Emetí a iodes a safety assessment were perf me ring the first 24 hours and the $n-24$ hours after anaesthesia.

Results-The pe entag of pa ents who were emesis free uri ours after anaesthesia is $85 \%$ ith granisetron and $90 \%$ with nosetron, respectively ( $p=$ 0.369); a responong rate during 24-48 ours afte naesthesia was $70 \%$ and 95\% $(p=0.003)$. No clinically serious a erse vents caused by the study drug we " server" "n any of the groups.

inc vion Prophylactic antiemetic t erapy th ramosetron is comparable mranisetron for the prevention of vomiting during 0-24 hours after anaesthesia in children undergoing strabismus

Department of Anaesthesiology, Toride Kyodo General Hospital, Toride City, Ibaraki, Japan Y Fujii

H Tanaka

Department of Ophthalmology M Ito

Correspondence to: Yoshitaka Fujii, Department of Anaesthesiology, University of Tsukuba Institute of Clinical Medicine, 2-1-1, Amakubo, Tsukuba City, Ibaraki 305-8576, Japan

yfujii@igaku.md.tsukuba.ac.jp

Accepted for publication 26 January 2001 emesis in patients receiving cytotoxic drugs. ${ }^{4}$ Granisetron reduces the incidence of vomiting following strabismus surgery in children. ${ }^{5}$ Ramosetron, (R)-5-[(1-methyl-3-indolyl) carboxyl]-4,5,6,7-tetrahydro-1H-benzimidazol hydrochloride (Nasea; Yamanouchi, Tokyo, Japan) is another new $5 \mathrm{HT}_{3}$ receptor antagonist, and has mormotent and longer acting properties again cispla induced emesis than granisetron. ${ }^{6}$ ophylactio herapy with ramosetron is more a ctive tha granisetron for the preventi of pos erat nausea and vomiting $w$ sin a $\$$ hou stanaesthetic period in womo un crgoing major gynaecological suriy. ${ }^{7}$ h ever, Aere have been no reports omparing b efficacy of ramosetron and gh isetron il children. This prospective, random d, double blinded study was designed to evaluat the efficacy and safety of granisetron and ramosetron for the prevention of postopative vomiting in children undergoing strabishus surgery.

\section{Methods}

The study was approved by our institutional ethics committee, and informed consent was obtained from the parents of 80 children (American Society of Anesthesiologists physical status I), aged 4-10 years, undergoing strabismus surgery (that is, operative procedure for eye muscles advancement (resection) and/or recession). Patients who had a history of motion sickness, previous postoperative vomiting, gastrointestinal disorders, or had had an antiemetic within 24 hours before surgery were excluded from participation because these patient related factors might contribute to postoperative vomiting. ${ }^{3}$

Patients were randomly assigned to receive intravenously granisetron $40 \mu \mathrm{g} / \mathrm{kg}$ or ramosetron $6 \mu \mathrm{g} / \mathrm{kg}(\mathrm{n}=40 \mathrm{of}$ each) at the completion of the surgical procedure. A randomisation list was generated and identical syringes containing each drug were prepared by personnel not involved in the study, according to the list. The dose of granisetron chosen in this study was used in our previous study. ${ }^{5}$ No data were available regarding the dose of ramosetron to be used in paediatric patients, but the dose used in the present study was extrapolated from the adult investigation.?

Patients were not allowed to have solid food after midnight before surgery. Clear liquids were permitted up to 3 hours before surgery. No preanaesthetic medications were administered. Anaesthesia was induced by increasing concentration of sevoflurane in $66 \%$ nitrous oxide $\left(\mathrm{N}_{2} \mathrm{O}\right)$ and oxygen $\left(\mathrm{O}_{2}\right)$ via mask. After -hydroxytryptamine type $3\left(5 \mathrm{HT}_{3}\right)$ receptor antagonist, and is effective for the treatment of 
Table 1 Patient demographic data

\begin{tabular}{lll}
\hline & $\begin{array}{l}\text { Granisetron } \\
(n=40)\end{array}$ & $\begin{array}{l}\text { Ramosetron } \\
(n=40)\end{array}$ \\
\hline Age (years) & $6.6(2.2)$ & $6.7(2.4)$ \\
Sex (male/female) & $20 / 20$ & $18 / 22$ \\
Height (cm) & $119.2(10.4)$ & $119.7(11.2)$ \\
Weight (kg) & $23.6(5.3)$ & $24.1(7.0)$ \\
Duration of surgery (min) & $48(10)$ & $47(12)$ \\
Duration of anaesthesia (min) & $71(10)$ & $69(11)$ \\
Muscle repaired (n) & $2.2(0.5)$ & $2.4(0.4)$ \\
Types of surgery (n) & & \\
$\quad$ Advancement (resection) & 2 & 3 \\
$\quad$ Recession & 3 & 3 \\
$\quad$ Advancement and recession & 35 & 34 \\
Analgesics administered postoperatively (n) & \\
$\quad$ Acetaminophen & 29 & 30 \\
$\quad$ Pentazocine & 5 & 5 \\
\hline
\end{tabular}

Values are mean $(\mathrm{SD})$ or number.

an inhalation induction of anaesthesia, atropine $0.01 \mathrm{mg} / \mathrm{kg}$ was given intravenously and tracheal intubation was facilitated with vecuronium $0.1 \mathrm{mg} / \mathrm{kg}$ intravenously. After tracheal intubation, anaesthesia was maintained with $\mathrm{N}_{2} \mathrm{O} / \mathrm{O}_{2} \quad(2: 1)$ and sevoflurane $1.0 \%-3.0 \%$ (inspired concentration). Ventilation was mechanically controlled and adjusted to maintain an end tidal carbon dioxide tension at 4.6-5.2 $\mathrm{kPa}$ using an anaesthetic/respiratory gas analyser. Neuromuscular block was achieved wit vecuronium and was antagonised by a combination of atropine $0.02 \mathrm{mg} / \mathrm{kg}$ and neos smine $0.04 \mathrm{mg} / \mathrm{kg}$ intravenously at the end of urgery. The trachea was extubated when the patient was awake. Rectal temperature was mo kored and maintained at $37^{\circ} \mathrm{C}$ (SD using water pads throughout surger Any neration, all patients were admitted $t^{t} c$ hospital and remained for a -0 , le of rays. Clear liquids were offere only reque ed by the patient, and other 91 in allowed for 4 hours or reo ery from anaesthesia. Postoperati nalgesia s provided by acetaminopher 15-_ $\mathrm{mg} / \mathrm{kg}$ roctally for mild pain and by entazocis $3 \mathrm{mg} / \mathrm{kg}$ intravenously for seve pain. ation, all episodes of emetic sympton (ching yomiting) during 0-24 hours nd -48 ars after anaesthesia were rerded do arsing staff without any knowledge which treatment each patient had received. These nurses observed the patients at various intervals according to the normal ward routine Id asked the parents about their children's postoperative condition (that is, no emesis, vomiting, retching). Vomiting was defined as the forceful expulsion of gastric contents from the mouth, and retching was defined as the laboured, spasmodic, rhythmic contraction of

Table 2 Number (\%) of patients experiencing no emesis, or with retching or vomiting during 0-24 hours and 24-48 hours after anaesthesia

\begin{tabular}{|c|c|c|c|c|}
\hline & $\begin{array}{l}\text { Granisetron } \\
(n=40)\end{array}$ & $\begin{array}{l}\text { Ramosetron } \\
(n=40)\end{array}$ & $p$ Value & $\begin{array}{l}\text { Relative risk } \\
(95 \% C I)\end{array}$ \\
\hline \multicolumn{5}{|c|}{$0-24$ hours after anaesthesia } \\
\hline No emesis & $34(85)$ & $36(90)$ & 0.369 & $0.94(0.82-1.09)$ \\
\hline Retching & $1(3)$ & $2(5)$ & 0.5 & $0.60(0.09-3.87)$ \\
\hline Vomiting & $6(15)$ & $4(10)$ & 0.369 & $1.50(0.55-4.06)$ \\
\hline \multicolumn{5}{|c|}{ 24-48 hours after anaesthesia } \\
\hline No emesis & $28(70)$ & $38(95)$ & 0.003 & $0.74(0.02-0.88)$ \\
\hline Retching & $5(13)$ & $0(0)$ & 0.027 & $13.0(0.90-188.42)$ \\
\hline Vomiting & $9(23)$ & $2(5)$ & 0.024 & $4.60(1.35-17.73)$ \\
\hline
\end{tabular}

Values are number (\%). the respiratory muscles, including the diaphragm, chest wall, and abdominal wall muscles, without the expulsion of gastric contents. $^{3}$ Nausea was not assessed as a separate entity in this study because of the young age of the patients. The problems (that is, adverse events due to the study drugs) were also recorded after by either questioning the children, interviewing the parents of patients, or observation by the nurses.

Patient data were analysed using ANOVA with Bonferroni's adjustment for multiple comparison and $\chi^{2}$ test. The number of patients with no emesis, or were retching or vomiting, and the incidence of adverse events were compared with Fisher's exact probability test. A $p$ value of $<0.05$ was considered significant. Values are expressed as mean (SD) or number (\%). Forty notients in each group were sufficient to det $\alpha$ a a. erence with $\alpha=0.05$ and power $(1 \beta)=0.8$.

\section{Results}

Patier profil and is mation on surgery and anaes esia are summarised in Table 1. The atme oroups ere comparable with regard patient cteristics and types of operath The perventage of patients with no emesis dur $\quad 0-24$ hours after anaesthesia was $85 \%$ with g nisetron and $90 \%$ with ramosetron, mespectively ( $\mathrm{p}=0.369$, relative risk 0.94 .82-1.09)); the corresponding rate during 4-48 hours after anaesthesia was $70 \%$ and $95 \%(p=0.003$, relative risk $0.74(0.62-0.88))$. Thus, an emesis-free episode during 24-48 hours after anaesthesia was greater in patients who had received ramosetron than in those who had received granisetron $(p<0.05)$ (Table 2). Clinically serious adverse events (excessive sedation, extrapyramidal symptoms) caused by the study drug were not observed in any of the groups.

\section{Discussion}

The reported incidence of vomiting after paediatric strabismus surgery varies from $48 \%$ to $85 \%$ when no prophylactic antiemetic is given. ${ }^{12}$ This incidence is higher than that associated with other surgical procedures in children. ${ }^{3}$ The cause of vomiting following paediatric strabismus surgery remains unclear, but is probably multifactorial. ${ }^{3}$ A number of factors including age, sex, obesity, a history of motion sickness, and/or previous postoperative vomiting, operative procedure, anaesthetic technique, and postoperative pain are considered to affect the incidence of postoperative vomiting. ${ }^{3}$ Surgical factors also include the impulses from the extrinsic eye muscles related to the vestibular nuclei III, IV, and VI of the medial longitudinal fasciculi. ${ }^{8}$ These vestibular nuclei lie in the brainstem reticular formation and are closely associated anatomically with the vomiting centre. In this study, however, the treatment groups were comparable with respect to patient characteristics, operative procedure, anaesthetics administered, and analgesics used postoperatively. A neuromuscular blocking drug is also an integral part of a balanced anaesthetic technique. The dose $(0.1 \mathrm{mg} / \mathrm{kg})$ of vecuronium 
used in the present study was used in our previous studies. ${ }^{57}$ Therefore, the differences in the number of patients experiencing no emesis between the groups can be attributed to the study drug. An emesis free episode observed in this study would be changed if such patient related factors were not controlled.

Granisetron is effective for the treatment of emesis induced by cancer chemotherapy. ${ }^{4}$ We have demonstrated that granisetron reduces the incidence of vomiting after paediatric strabismus surgery, ${ }^{5}$ and have also shown that granisetron $40 \mu \mathrm{g} / \mathrm{kg}$ is the minimum effective dose for the prevention of postoperative vomiting. ${ }^{9}$ Therefore, the same dose of granisetron was administered in the present study. The precise mechanism for the prevention of postoperative vomiting remains unclear, but it has been suggested that granisetron may act on sites containing $5 \mathrm{HT}_{3}$ receptor with demonstrated antiemetic effects. ${ }^{10}$ Ramosetron, another $5 \mathrm{HT}_{3}$ receptor antagonist, is effective for the treatment of cisplatin induced emesis. ${ }^{11}$ Our results demonstrated that ramosetron, like granisetron, reduces the incidence of vomiting after strabismus surgery in children. The exact mechanism of ramosetron for the prevention postoperative vomiting is unknown, but it ma act at the area postrema and the creus tractus solitarius, which contain a nu ber of $5 \mathrm{HT}_{3}$ receptors. ${ }^{12}$ Thus, the possibl mechanism of ramosetron for the preven $n$ of postoperative vomiting is sir granisetron. The dose of ramos ron rysed for children has not been establ he, butwas extrapolated from cli

In this study, we patients experiench no nung 24-48 hours after ar esthe was greater in those who had $r$ ved ram tron than in those who had cein graniseth $(\mathrm{p}=0.003)$, and also $s^{1}$ wed no ifferences in emesis free epis es during $0-\boldsymbol{C}$ hours after anaesthesia $\mathrm{b}$ ween $\mathrm{e}$ groups $(\mathrm{p}=0.369)$. These fin ougges that ramosetron has a potent ntie, tic ef $c t$ that lasts up to 48 hours. The act re. for the difference in effectiveness strueen granisetron and ramosetron is not known, but may be related to the elimination half life (granisetron 3.1 hours versus ramoset5.8 hours $)^{13}{ }^{14}$ and/or the affinities of $5 \mathrm{HT}_{3}$ receptor antagonists (granisetron 1 versus ramosetron 41).

Granisetron lacks the sedative, dysphoric, and extrapyramidal symptoms associated with other non-5 $5 \mathrm{HT}_{3}$ receptor antagonists such as droperidol and metoclopramide. ${ }^{15}$ We have recently demonstrated that granisetron is relatively free of adverse effects and is also safe for the prevention of vomiting following paediatric strabismus surgery. ${ }^{5}$ Adverse events caused by the study drug in the present study were not clinically serious in either group. Thus, ramosetron, like granisetron, is considered to be relatively free of adverse effects.

The major deficiency in this study design is the failure to include a control group receiving placebo. We have already shown that the antiemetic efficacy of granisetron is superior to placebo for the prevention of vomiting after strabismus surgery in children. ${ }^{5}$ Moreover, Aspinal and Goodman ${ }^{16}$ have suggested that placebo controlled trials may be unethical if active drugs are available because postoperative nausea and vomiting are common and distressing symptoms against which there is effective treatment. Therefore, a control group was not included in the present study.

In Japan, a $5 \mathrm{HT}_{3}$ receptor antagonist, granisetron ( $\$ 102.00$ for $3 \mathrm{mg}$ ) or ramosetron ( $\$ 100.00$ for $0.3 \mathrm{mg}$ ), is much more expensive than other commonly used and well established antiemetics, droperidol (\$1.80 for 1.25 $\mathrm{mg}$ ) and metoclopramide ( $\$ 0.60$ for $10 \mathrm{mg}$ ). However, the use of these non-5- $\mathrm{HT}_{3}$ receptors as antiemetics has been limited because these drugs occasionally cause excessive sedation and/or extrapyrami-1 symptoms. ${ }^{3}$ Therefore, the choice of ar emeti should not be based solely on th calculation of costs, but also should tal in consider fion the preference of patie

In concly on, ophylactic antiemetic thera w ramosetron is comparable to aniset for th prevention of vomiting dur0-24 w after anaesthesia in children rgoing scrabismus surgery. During 24-48 hou after anaesthesia, ramosetron is more effectiv than granisetron for prophylaxis gainst postoperative vomiting

1 Abramowitz MD, Oh TH, Epstein BS, et al. The antiemetic effect of droperidol following outpatient strabismus surgery in children. Anesthesiology 1983;59:579-83.

2 Lerman J, Eustis S, Smith DR. Effect of droperidol pretreatment on postanesthetic vomiting in children undergoing trabismus surgery. Anesthesiology 1986;65:322-5.

3 Watcha MF, White PF. Postoperative nausea and vomiting. Its etiology, treatment, and prevention. Anesthesiology 1992;77:162-84.

4 Bermudez J, Boyle EA, Minter WD, et al. The antiemetic potential of the 5-hydroxytryptamine3 receptor antagonist BRL 43694. Br F Cancer 1988;58:644-50.

5 Fujii Y, Tanaka H, Toyooka H. Granisetron reduces vomiting after strabismus surgery and tonsillectomy in children. Can $\mathcal{F}$ Anaesth 1996;43:35-8.

6 Fujihara A, Akuzawa S, Miyata K, et al. Ramosetron hydrochloride: affinity for cloned human 5-HT3 receptor and 5-HT3 receptor antagonistic and antiemetic effect in the ferret. Lab Clin 1996;30:1965-72.

7 Fujii Y, Saitoh Y, Tanaka H, et al. Comparison of ramosetron and granisetron for preventing postoperative nausea and vomiting after gynecologic suregry. Anesth Analg 1999; 9::476-9.

8 Warner LO, Rogers MD, Martino LD, et al. Intravenous lidocaine reduces the incidence of vomiting in children after surgery to correct strabismus. Anesthesiology 1988;68: 618-21.

9 Fujii Y, Toyooka H, Tanaka H. Effective dose of granisetron for preventing postoperative emesis in children. Can $\mathcal{f}$ Anaesth 1996;43:660-4.

10 Carmichael J, Cantwell BMJ, Edwards CM, et al. A pharmacokinetic study of granisetron (BRL 43694A), a selective 5-HT3 receptor antagonist: correlation of anti-emetic
response. Cancer Chemother Pharmacol 1989;24:45-9.

11 Noda K, Ikeda M, Yoshida O, et al. Clinical evaluation of ramosetron against the nausea and vomiting induced by ramosetron against the nausea and vomiting induced by
anticancer drugs. Fpn f Clin Exp Med 1994;71:2765-76.

12 Kamato T, Ito H, Nagakura Y, et al. Mechanism of cisplatinand $m$-chlorophenylbiguanide-induced emesis in ferret. Eur f Pharmacol 1993;238:369-76.

13 Kawabata Y, Sakiyama H, Muto S, et al. Clinical evaluation and pharmacokinetics of ramosetron against the nausea and vomiting induced by anticancer drugs. Nishinihon $\mathcal{F}$ Urol 1994;56:1445-56.

14 Kumakura H, Koyanagi J, Nishioka Y, et al. Phase I study of granisetron: pharmacokinetics of granisetron following single and repeat intravenous drips infusion in Japanese healthy volunteers. $\mathcal{F}$ Clin Ther Med 1990;5:25-34.

15 Yarker YE, McTavish D. Granisetron. An update of its therapeutic use in nausea and vomiting induced by antinetherapeutic use in nausea and vomiting ind

16 Aspinall RL, Goodman NW. Denial of effective treatment and poor quality of clinical information in placebo controlled trials of ondansetron for postoperative nausea and vomiting: a review of published trials. BMF 1995;311:844-6. 


\section{Retraction notice}

\section{Ramosetron compared with granisetron for the prevention of vomiting following strabismus surgery in children}

Yoshitaka Fujiii, ${ }^{1}$ Hiroyoshi Tanakaa, ${ }^{1}$ Mutsuko Itob ${ }^{2}$

${ }^{1}$ Department of Anaesthesiology, Toride Kyodo General Hospital, Toride City, Ibaraki, Japan, ${ }^{2}$ Department of Ophthalmology

Correspondence to: Yoshitaka Fujii, Department of Anaesthesiology, University of Tsukuba Institute of Clinical Medicine, 2-1-1, Amakubo, Tsukuba City, Ibaraki 305-8576, Japanyfujii@igaku.md.tsukuba.ac.jp

Notice of formal retraction of article by Dr Y. Fujii. This article is being retracted as a result of:

(1) Overwhelming evidence of fabrication, related to the fact that the distributions of many variables reported by Dr Fujii in these studies could not have occurred by chance; ${ }^{12}$ and

(2) The inability of Dr Fujii's institutions to attest to the integrity of the study and/or its data conducted under their auspices, as set out in the Joint Editors-in-Chief Request for Determination of April 9, 2012. ${ }^{3}$

Br J Ophthalmol 2016;100:150. doi:10.1136/bjo.85.6.670ret

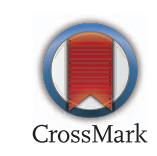

\section{REFERENCES}

1 Carlisle JB. The analysis of 168 randomised controlled trials to test data integrity. Anaesthesia 2012;67:521-37.

2 Kranke P, Apfel CC, Roewer N. Reported data on granisetron and postoperative nausea and vomiting by Fujii et al. are incredibly nice! Fujii Y, Response. Anesth Analg 2000;90:1004-7

3 http://www.oxfordjournals.org/our_journals/bjaint/fujii_joint_editorial_request_regarding_dr_yoshitaka_fuji.pdf 